JAMP: Jurnal Adminitrasi dan Manajemen Pendidikan

Volume 4 Nomor 1 Maret 2021, Hal : $24-31$

Tersedia Online di http://journal2.um.ac.id/index.php/jamp/

ISSN 2615-8574 (online)

JAINP

JURNAL ADMINISTRASI DAN MANAJEMEN PENDIDIKAN

\title{
MODEL SISTEM INFORMASI MANAJEMEN TERPADU UNTUK MENINGKATKAN MUTU LAYANAN PENDIDIKAN
}

\author{
Anis Farida ${ }^{1}$ \\ Rudy Wahyono ${ }^{2}$ \\ Fajar Supanto ${ }^{3}$ \\ ${ }^{1}$ SMKN 1 Kepanjen \\ ${ }^{2}$ Universitas Merdeka Malang \\ ${ }^{3}$ Universitas Merdeka Malang \\ Email: anisfarida96@gmail.com
}

\begin{abstract}
The purpose of this study is to describe the Integrated Management Information System Model, obstacles and strategies to overcome obstacles and to analyze their implementation in improving educational services in Vocational High Schools, Malang Regency. This study used a qualitative approach, data collection was carried out using interview, observation, and documentation techniques, the sampling method was purposive sampling, namely in three Vocational High Schools that had implemented an integrated management information system and research informants namely the principal, vice principal, head of governance business, teacher representatives and student representatives. The result of this research is an integrated management information system model in SMK Malang Regency using the Master-Web application which is implemented in the curriculum, student affairs, public relations, finance, workforce, and counseling sections. The information generated can be accessed by the principal and used as material for decision making to improve the quality of the school. The obstacles are some human resources who do not master IT, are not disciplined in inputting data, lack of care, lack of infrastructure, and weak system security.
\end{abstract}

Keywords: Integrated management information system model; education services; SMK

\begin{abstract}
Abstrak: Tujuan penelitian ini adalah untuk mendeskripsikan Model Sistem Informasi Manajemen terpadu, hambatan dan strategi mengatasi hambatan serta menganalisis implementasinya dalam meningkatkan layanan pendidikan di Sekolah Menengah Kejuruan Kabupaten Malang. Penelitian ini menggunakan pendekatan kualitatif, pengumpulan data dilakukan dengan menggunakan teknik wawancara, observasi, dan dokumentasi, metode pengambilan sampel dengan purposive sampling, yaitu di tiga SMK yang telah mengimplementasikan sistem informasi manajemen terpadu dan informan penelitian yaitu kepala sekolah, wakil kepala sekolah, kepala tata usaha, perwakilan guru dan perwakilan siswa. Hasil penelitian adalah Model sistem informasi manajemen terpadu di SMK Kabupaten Malang menggunakan aplikasi Master-Web yang diimplementasikan di bagian kurikulum, kesiswaan, hubungan masyarakat, keuangan, ketenagaan, dan bimbingan konseling. Informasi yang dihasilkan dapat diakses oleh kepala sekolah dan digunakan sebagai bahan pengambilan keputusan untuk meningkatkan mutu sekolah. Hambatannya adalah beberapa SDM yang tidak menguasai IT, tidak disiplin dalam menginput data, kurang peduli, kurangnya sarana prasarana, dan lemahnya keamanan sistem.
\end{abstract}

Kata kunci: Model sistem informasi manajemen terpadu; layanan pendidikan; SMK 
Lembaga pendidikan memerlukan suatu manajemen yang terpadu untuk menyajikan informasi maupun pelaporan yang cepat dan akurat. Informasi ataupun pelaporan yang disajikan dengan cepat dapat dijadikan sebagai pertimbangan untuk menganalisa dan mengambil keputusan dengan baik dan benar. Hal tersebut tentunya sangat sulit dilakukan jika dikerjakan secara manual dan tidak menggunakan teknologi informasi yang terpadu antar bagian di intern lembaga pendidikan tersebut sebagai dasar dalam manajemen. Yakub \& Hisbanarto (2014) menyatakan bahwa salah satu kebutuhan manajemen pendidikan saat ini adalah penyediaan akses data dan informasi dari proses menghimpun, mendata, mengolah, menggandakan, menyimpan dan mengirim.

Berdasarkan Permendikbud No 34 tahun 2018 bahwa setiap SMK/MAK memerlukan Standar Pengelolaan yang salah satunya adalah implementasi Sistem Informasi Manajemen. Dengan pengelolaan ini diharapkan mampu menyelenggarakan pendidikan dan pembelajaran yang berkualitas untuk menyiapkan kualitas lulusan sesuai dengan tujuan yang telah ditetapkan dan memenuhi kebutuhan dunia usaha/dunia industri pada masa mendatang.

Sistem informasi manajemen (SIM) adalah sistem yang mengolah dan mengorganisasi data/informasi yang berguna untuk mendukung pelaksanaan tugas organisasi (Utama, 2019). Faktanya meskipun SIM yang terpadu merupakan hal yang sangat penting dalam pengelolaan SMK/MAK tetapi masih banyak sekolah yang belum mengimplementasikannya. Hasil observasi awal, dari 139 SMK Negeri dan swasta yang ada di Kabupaten Malang, hanya ada 6 (enam) SMK yang telah mengimplementasikan SIM Terpadu. SMK yang telah mengimplementasikan pun belum pernah melakukan evaluasi pelaksanaannya.

Penelitian tentang implementasi sistem informasi manajemen di Sekolah Menengah Kejuruan sudah banyak dilakukan oleh peneliti-peneliti sebelumnya, tetapi sebagian besar hanya meneliti implementasi dalam bidang akademik ataupun pengembangannya. Utama (2019) dalam penelitiannya yang berjudul "Implementasi sistem informasi manajemen di Sekolah Menengah Kejuruan (SMK) Muhammadiyah 1 Padang". Hasilnya adalah implementasi sistem informasi manajemen di SMK Muhammadiyah 1 Padang dapat meningkatkan efektifitas dan efisiensi kerja, mengurangi penggunaan kertas dan tinta, serta merapikan dan mengamankan data. Wahyudi (2015) dalam penelitiannya yang berjudul "Implementasi Sistem informasi Manajemen Akademik Berbasis Web di SMK Negeri 3 Metro" membahas mulai dari perencanaan, pengorganisasian, pelaksanaan dan evaluasi dari sistem informasi manajemen pada bagian akademik sekolah. Penelitian implementasi SIM terpadu sudah pernah dilakukan oleh Aditya (2011), hasilnya adalah implementasi SIM Terpadu dapat meningkatkan kualitas pengelolaan informasi sebagai media komunikasi yang efektif dan efisien bagi sekolah. Melalui penelitian ini, penulis membahas model sistem informasi manajemen terpadu dalam kaitannya dengan strategi peningkatan kualitas layanan pendidikan di SMK Kabupaten Malang Propinsi Jawa Timur.

Tujuan penelitian ini adalah untuk mendeskripsikan model Sistem Informasi Manajemen terpadu di SMK, untuk mengetahui hambatan, strategi mengatasi hambatan yang terjadi, dan menganalisis dampak implementasi terhadap peningkatan mutu layanan pendidikan.

\section{METODE}

Penelitian ini menggunakan pendekatan kualitatif. Menurut Kriek dan Miller dalam Moleong (2002:4) bahwa pendekatan kualitatif bergantung pada pengamatan manusia. Desain Penelitian termasuk studi naratif karena peneliti fokus pada narasi/cerita/deskripsi tentang peristiwa yang terkait dengan pengalaman manusia dalam mengimplementasikan SIM Terpadu di sekolah, termasuk hambatan dan upaya apa yang dilakukan dalam rangka meningkatkan mutu layanan pendidikan.

Sampel (informan) dalam penelitian ini ditentukan secara purposive yaitu pengambilan berdasarkan kriteria tertentu (Sugiyono, 2012), artinya sampel diambil dengan pertimbangan dapat memberikan informasi yang lengkap kepada peneliti. Lokasi peneltian di tiga sekolah yaitu SMK Negeri 1 Kepanjen, SMK Negeri 1 Turen dan SMK Muhammadiyah 1 Kepanjen yang telah mengimplementasikan SIM Terpadu. Informannya adalah Kepala sekolah, wakil kepala sekolah, kepala tata usaha, perwakilan guru, operator sekolah, dan perwakilan siswa. Pengumpulan data dilakukan dengan menggunakan teknik wawancara, observasi, dan dokumentasi. 
Uji keabsahan data meliputi uji credibility, transferability, dependability, dan confirmability (Sugiyono, 2012:270). Uji kredibilitas dengan melakukan perpanjangan pengamatan, yaitu penulis mendatangi lokasi penelitian beberapa kali, meningkatkan kecermatan dalam penelitian yaitu dengan mencatat dan merekam hal-hal penting yang mendukung kegiatan penelitian di tempat lokasi sebagai bahan mendeskripsikan hasil penelitian, dan melakukan triangulasi yaitu dengan melakukan pengecekan data dari berbagai sumber dengan berbagai waktu. Tranferability dengan memberikan gambaran hasil penelitian secara jelas, terperinci dan dapat dipercaya. Uji dependability, peneliti benar-benar terjun ke lapangan obyek penelitian beberapa kali untuk mendapatkan data penelitian, memilih sumber data, melaksanakan analisis data, melakukan uji keabsahan data, sampai pada pembuatan laporan hasil pengamatan. Uji confirmability dengan menunjukkan hasil penelitian untuk disepakati oleh beberapa orang di lokasi obyek penelitian.

Analisis data menggunakan Model Miles dan Huberman dalam Sugiyono (2012) yang aktifitasya meliputi mereduksi data yaitu data yang diperoleh dirinci dan dipilah serta dianalisis sesuai focus penelitian, menyajikan data secara lengkap sesuai focus penelitian, dan memverifikasi data dengan cara menyimpulkan hasil reduksi dan penyajian data sebelumnya.

\section{HASIL}

Model sistem informasi manajemen terpadu yang diimplementasikan di SMK Kabupaten Malang dikenal dengan sebutan Master-Web (Manajemen Aplikasi Sekolah Terpadu Berbasis WEB). Aplikasi Master-Web adalah sistem informasi yang dapat diakses oleh semua komunitas sekolah baik itu oleh siswa, wali siswa, karyawan, guru kepala sekolah sampai pihak luar. Master-Web dapat dijalankan dimanapun selama komputer itu terhubung di jaringan dan mempunyai program internet explorer karena program ini dijalankan melalui alamat internet hingga sistem ini bisa dijalankan melalui intranet (internet local) ataupun internet umum dan dapat diinstal di Windows atau Linux karena Manajemen Aplikasi Sekolah Terpadu Berbasis Web (Master-Web) sudah memanfaatkan web server APACHE.

Perangkat yang dibutuhkan untuk mengimplementasikan Master-Web ini terdiri dari: (1) Perangkat hardware (komputer client/terminal, mesin presensi guru dan karyawan/finger, mesin presensi siswa/ finger, server terdiri dari: database server \& web server), (2) perangkat jaringan yaitu hub, cable/ wireless/internet, lan card, dan (3) perangkat software, yaitu sistem operasi client (windows), sistem operasi server (windows), dan database server (SQL SERVER)

Master-Web dirancang menggunakan teknologi berbasis web sehingga program ini sangat mudah untuk di install di sisi server dan sangat cepat jika diakses dari sisi client. Sistem dikembangkan agar dapat diakses melalui Internet (online) dengan mudah, tanpa biaya besar, serta keamanan data yang terjamin. Hal ini memungkinkan setiap user yang memiliki hak dapat mengakses informasi sekolah, dimanapun dan kapanpun.

Master-Web dibagi menjadi beberapa modul yang difungsikan pada masing-masing bagian di sekolah, sehingga setiap bagian dapat mengakses data sewaktu - waktu secara cepat, tepat dan akurat. Modul dalam Master-Web di sekolah terdiri dari modul PPDB, modul kesiswaan, modul kurikulum, modul student finance, modul humas, modul personalia, modul bendahara, modul manajemen, modul guru, modul karyawan, modul siswa, modul wali siswa, modul persuratan, modul ujian berbasis komputer, modul nilai dan rapor online.

Modul akun manajemen diperuntukkan bagi kepala sekolah yang berisi informasi jumlah siswa dan data guru serta menu-menu laporan tiap bagian di sekolah baik dari kurikulum, humas, kesiswaan, personalia, keuangan, gaji pegawai dan jurnal guru/karyawan. Modul kesiswaan diakses oleh Wakil kepala sekolah bagian kesiswaan dengan menu berupa data jumlah siswa dan jumlah pegawai di tahun pelajaran yang sedang berjalan yang diperoleh dari bagian operator sekolah. Selain itu terdapat menu awal yang berupa setup data (tahun akademik, jurusan, kelas, rombongan belajar, agama, jenis ektrakurikuler, jenis pelanggaran, sanksi absensi), menu entri data (nilai ekstrakurikuler, pelanggaran siswa, surat izin masuk/keluar, prestasi siswa, nama siswa), menu entri kegiatan kesiswaan (jurnal dan program kerja). 
Sedangkan laporan yang dihasilkan pada bagian kesiswaan berupa laporan presensi siswa harian, mingguan maupun bulanan serta rekap siswa yang tidak melakukan presensi, laporan pelanggaran per siswa maupun per jurusan, daftar siswa aktif, agama siswa aktif, laporan nilai ekstrakurikuler serta menu grafik berupa presensi siswa, asal sekolah, dan siswa aktif, lihat Gambar 1.

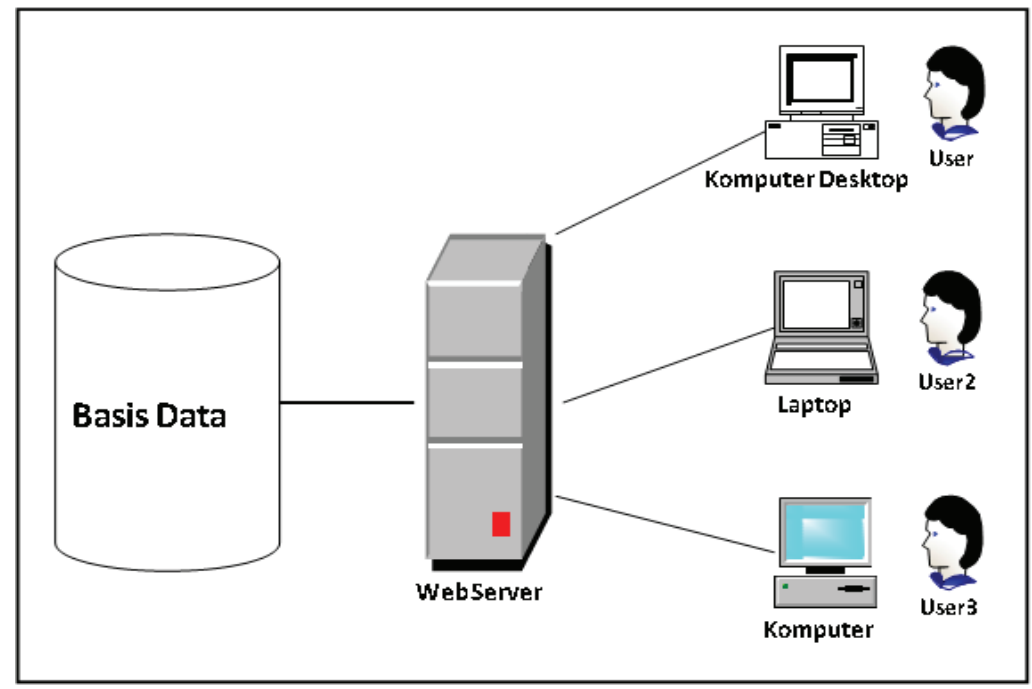

Gambar 1: Model aplikasi Master-Web

Modul kurikulum merupakan hak akses dari wakil kepala sekolah bagian kurikulum yang berisi menu proses (entri nilai ujian, entri nilai kompetensi dasar), setup (penjurusan kelas, kelompok mata pelajaran, mata pelajaran, pengajar, perwalian kelas, jam belajar, jadwal KBM,), Ujian berbasis Komputer/UBK (berisi jadwal UBK, reset, dan soal UBK), dan laporan berupa nilai rapor tengah semester dan nilai akhir semester.

Modul kehumasan di Master-Web berisi tentang setup prakerin (praktik Kerja industry) yang terdiri dari nilai aspek, tempat prakerin, dan biodata perusahaan yang bekerjasama, setup alumni yang terdiri dari pemetaan alumni, perguruan tinggi, perusahaan dan wirausaha, entri nilai prakerin dan penelusuran alumni. Informasi yang dihasilkan pada bagian humas adalah berupa laporan persebaran alumni, penelusuran alumni, perguruan tinggi, perusahaan mitra BKK, laporan prakerin, tempat prakerin, nili prakerin, status siswa prakerin, username dan password siswa, jurnal monitoring, jurnal harian siswa, dan laporan prakerin.

Modul akun siswa menu yang ada berupa entri data tentang daftar ulang saat pertama kali masuk di sekolah, fasilitas mengubah paswordnya, pengisian jurnal prakerin, polling guru dan menu absensi siswa. Sedangkan Modul guru berisi tentang riwayat kepegawaian, nilai pengetahuan, nilai ketrampilan, nilai ujian \& rapor, ekspor impor nilai, ledger nilai, ledger wali kelas, ekspor nilai ujian, ubah password, jurnal mengajar guru dan fasilitas download dokumen pribadi. Untuk modul bimbingan konseling memuat menu entri surat ijin masuk/keluar, home visit, konseling, pelaksanaan bimbingan kelompok, bimbingan klasikal, konsultasi, alih tangan kasus, wawancara dengan orang tua/wali.

Modul personalia adalah hak akses dari kepala Tata Usaha di sekolah yang berisi entri presensi guru dan karyawan, absensi guru dan karyawan, riwayat gaji berkala, data guru dan pegawai, mutasi guru dan pegawai, riwayat jabatan, riwayat kepangkatan, riwayat pendidikan, surat masuk, disposisi surat masuk dan surat keluar. Modul bendahara hanya dapat diakses oleh bendahara pengeluaran dan kepala sekolah saja. Fasilitas yang ada adalah entri jurnal, RKAS, setup arus kas BOS, laporan SPP, laporan penanggung jawab, laporan insidental, dan laporan komite. Modul student finance merupakan hak akses dari bendahara penerimaan pembayaran siswa yang dilengkapidengan fasilitas setup (jenis tagihan, biaya tagihan, perkiraan tagihan, dan perkiraan kas), menu proses (tagihan, pembayaran tagihan, valiidasi pembayaran), serta menu laporan. 


\section{PEMBAHASAN}

Implementasi Sistem informasi manajemen di SMK Kabupaten Malang dengan menggunakan model Aplikasi Master-Web sudah baik, karena dari proses sampai menghasilkan informasi berupa laporan yang bermanfaat bagi pengambil keputusan berjalan cepat, tepat dan akurat. Hanya satu kali proses penginputan data otomatis dapat dimanfaatkan oleh bagian-bagian lain di sekolah yang membutuhkan sehingga tidak perlu mengulang ulang proses input data. Hal ini sesuai dengan pendapat Prasojo (2013) bahwa pemanfaatan SIM pendidikan di sekolah diantaranya dapat meningkatkan akses informasi sekolah, meningkatkan efisiensi kegiatan sekolah serta meningkatkan kualitas sekolah.

Sebelum mengimplementasikan SIM terpadu pihak sekolah sudah melakukan sosialisasi ke semua warga sekolah. Sosialisasi menurut kamus besar Bahasa Indonesia berarti upaya memasyarakatkan sesuatu sehingga menjadi diketahui, dimengerti, dan dipahami oleh warga. Sosialisasi dilakukan melalui rapat dinas maupun secara individu sesuai tupoksinya masing masing. Sosialisasi penting agar semua orang yang berperan dalam implementasi SIM Terpadu dapat menjalankan tugasnya dengan baik. Tanpa adanya sosialisasi maka bisa dipastikan apapun tujuan program tidak tercapai dengan baik. Menurut O’Brien (dalam Rusdiana, 2018:95) SIM merupakan kombinasi yang teratur antara manusia, perangkat keras, perangkat lunak, jaringan komunikasi, dan sumber data yang mengumpulkan, mengubah, dan menyebarkan informasi dalam lembaga.

Informasi yang dihasilkan tiap bagian sesuai kebutuhan bagian tersebut. Informasi bagian kurikulum mulai dari pra pembelajaran, proses hingga evaluasi sudah bisa diimplementasikan dengan baik, sehingga SIM Terpadu sangat membantu kelancaran pelaksanaan proses belajar mengajar di sekolah. Informasi yang dihasilkan bagian kesiswaan, kehumasan dan kepersonaliaan juga sudah cukup memfasilitasi kebutuhan informasi pada bagian tersebut sehingga membantu kelancaran tugas dan fungsinya. Hal ini sesuai dengan teori Davis, B.G (2002:3) yang mengatakan bahwa sistem informasi manajemen adalah sebuah sistem terpadu untuk menyajikan informasi yang berguna mendukung fungsi operasi, manajemen dan pengambilan keputusan dalam sebuah organisasi.

Manfaat implementasi SIM terpadu di SMK Kabupaten Malang yang paling dirasakan adalah pada bagian adminstrasi keuangan sekolah. Karena pada bagian keuangan satu-satunya bagian yang terupdate baik pemasukan maupun pengeluaran harus terentri setiap hari. Dengan memanfaarkan Master-Web sekolah dapat mencegah adanya kekeliruan/kebocoran/penyimpangan penggunaan dana dari rencana semula. Manfaat lainnya adalah penyelenggaraan pendidikan dapat dilakukan lebih efisien dan efektif sesuai tujuan. Hal ini sesuai dengan bunyi Undang Undang No. 20 tahun 2003 pasal 48 bahwa dalam pengelolaan dana pendidikan harus berprinsip keadilan, efisiensi, efektif, tranparansi dan akuntabilitas publik.

Hambatan dalam mengimplementasikan sistem informasi manajemen terpadu di SMK Kabupaten Malang tiap bagian di sekolah tidak sama. Sebagian besar kendalanya dari segi sumber daya manusia yaitu kemampuan IT, adanya kesalahan input data, kurangnya kepedulian dari penginput data yang berakibat pada bagian lainnya. Kemudian kendala dari segi sistem yang berupa output data yang tidak sesuai dan keamanan yang belum maksimal, dari segi sarana prasarana yang kurang seperti kapasitas internet, dan kendala kurangnya komunikasi antar pihak yang berkaitan.

Rochaety (2009: 13) menyatakan bahwa untuk menerapkan SIM pendidikan yang terpadu dan mempunyai kapabilitas untuk mendukung keberhasilan dunia pendidikan, diperlukan adanya keseimbangan antara sumber daya yang tersedia dengan sumber daya manusia yang memiliki skills dalam mengoperasikan SIM sekolah seperti komputer serta adanya dana untuk pengadaan perangkat komputer yang canggih.

Keamanan informasi juga salah satu aspek penting dari sebuah sistem untuk melindungi komputer dan non peralatan komputer, fasilitas, data, dan informasi dari penyalahgunaan orang yang tidak bertanggungjawab, sehingga kerahasiaan, ketersediaan, dan integritas di dalam sumber daya informasi dalam lembaga terjaga. Selain itu untuk mencegah adanya potensi kerugian material, mengurangi resiko penyalahgunaan data/informasi, dan memperkecil peluang tindakan criminal. Oleh karena itu tim pengembang aplikasi sistem informasi manajemen terpadu harus memberi jaminan keamanan untuk melindungi data sekolah. 
Untuk mengatasi hambatan-hambatan implementasi SIM Terpadu yang ada di SMK Kabupaten Malang, yang telah dilakukan oleh pihak sekolah diantaranya:

a. Memberikan pelatihan IT.

Menurut Rochaety (2009: 112) bahwa pendidikan dan pelatihan sangat penting untuk meningkatkan pengetahuan dan kemampuan sumber daya manusia agar mampu memberikan layanan yang bermutu kepada para pelanggannya.

b. Pengawasan dalam manajemen

Menurut Siagian (dalam Rusdiana, 2018: 120) yang dimaksud pengawasan yaitu proses pengamatan pelaksanaan semua kegiatan organisasi untuk menjamin semua pekerjaan yang sedang dilaksanakan dapat berjalan sesuai rencana yang telah ditentukan sebelumnya.

c. Menyusun visi bersama

Keamanan sistem informasi manajemen sangat penting untuk menjamin keutuhan dan kualitas data maupun informasi yang dihasilkan baik dari faktor kesengajaan maupun masalah tehnis. Upaya yang dilakukan yaitu dengan menyusun visi bersama untuk melindungi dan mengamankan data dan informasi. Visi yang disusun dijabarkan dalam bentuk prosedur manajemen kendali sehingga semua komponen dalam organisasi ikut terlibat dalam pengamanan (Rochaety, 2009: 89).

d. Menciptakan komunikasi yang harmonis

Banyak sekali permasalahan yang timbul dikarenakan kurangnya komunikasi yang harmonis antar personal, antar manajemen maupun antar lembaga. Komunikasi yang harmonis menghasilkan kesadaran, pengertian, dukungan, keterlibatan dan akhirnya tercipta komitmen bersama. Hal ini sesuai dengan pendapat Rochaety (2009:146) bahwa Nilai-nilai yang perlu dimiliki untuk menciptakan hubungan yang harmonis dalam lembaga pendidikan adalah kerjasama (teamwork), keterbukaan (openess), kepercayaan (trust), perhatian kepada sesame (concern for people), keterlibatan (involvement), dan sebagainya.

Strategi mengatasi hambatan dalam pengimplementasian SIM terpadu tidak lepas dari peran manajemen dalam mengontrol dan mengevaluasi kebijakan implementasi itu sendiri. Nugroho (2004:163) mendeskripsikan pelaksanaan atau implementasi kebijakan dalam konteks manajemen berada di dalam kerangka pengorganisasian dan pengendalian. Ketika kebijakan sudah dibuat, maka tugas selanjutnnya adalah mengorganisasikan, melaksanakan kepemimpinan dan melakukan pengendalian pelaksanaan kebijakan tersebut. Kegiatan dalam manajemen implementasi kebijakan dapat disusun melalui: implementasi strategi, pengorganisasian, penggerakkan dan kepemimpinan, serta pengendalian. Untuk manajmen sekolah yang baik, triwiyanto (2019:110) mengatakan diperlukan prinsip kemandirian, keadilan, keterbukaan, kemitraan, partisipatif, efisiensi, dan akuntabilitas menjadi palang pintu keberhasilan.

Dari bagian-bagian sistem informasi manajemen terpadu yang diimplementasikan di SMK Kabupaten Malang (MASTER-WEB) dapat diketahui bahwa implementasi SIM terpadu memuat informasi informasi yang dibutuhkan oleh pelanggan sekolah yaitu, siswa, orang tua, guru ataupun pihak lain yang terkait (dinas pendidikan atau pun dunia usaha/dunia industri). Berikut ini adalah manfaat layanan pendidikan dalan implementasi SIM Terpadu di SMK Kabupaten Malang yang dinyatakan dalam bentuk Tabel 1 .

Dari Tabel 1 dapat diketahui bahwa dengan diimplementasikannya Master-Web dengan baik membawa dampak pada peningkatan pelayanan pendidikan di sekolah. Dalam dunia pendidikan layanan terbaik tidak hanya diberikan kepada siswa atau orang tua siswa saja tetapi juga harus dberikan kepada para guru dan pegawai agar mereka lebih optimal dalam bekerja sama sehingga akan memberi dampak terhadap mutu layanan yang diberikan. Semua kegiatan pemenuhan pelayanan yang berkualitas terhadap pelanggan adalah sebagai salah satu upaya sekolah dalam meningkatkan mutu sekolah. 
Tabel 1. Bentuk Layanan Pendidikan melalui Master-Web

\begin{tabular}{|c|c|}
\hline Pelanggan & Bentuk Layanan \\
\hline \multirow[t]{4}{*}{ Siswa } & - Dapat mengakses materi pelajaran di Master-Web secara online \\
\hline & - Dapat mengetahui nilai hasil belajar (Rapor) secara online \\
\hline & - Dapat melakukan presensi secara online \\
\hline & $\begin{array}{l}\text { - Dapat mengisi jurnal secara online meskipun saat berada di tempat Praktik } \\
\text { Kerja lapangan }\end{array}$ \\
\hline \multirow[t]{3}{*}{ Wali siswa } & - Dapat megetahui dan memantau presensi kehadiran puteranya secara online \\
\hline & - Dapat mengetahui jumlah tagihan administrasi keuangan puteranya dari sekolah \\
\hline & - Dapat mengetahui jenis pelanggaran puteranya secara online \\
\hline \multirow[t]{4}{*}{ Guru } & $\begin{array}{l}\text { - Dapat mengisi jurnal pembelajaran secara online yang sewaktu waktu bisa } \\
\text { diprint untuk keperluan laporan individu di tingkat dinas pendidikan }\end{array}$ \\
\hline & - Dapat mengisi daftar hadir siswa saat KBM berlangsung secara online \\
\hline & - Dapat menginput nilai siswa secara online dimana pun dan kapan pun. \\
\hline & - Dapat memproses raport secara online tanpa harus datang ke sekolah \\
\hline \multirow{2}{*}{\multicolumn{2}{|c|}{ aman, dan sewaktu waktu bisa diunduh. }} \\
\hline & \\
\hline \multicolumn{2}{|c|}{$\begin{array}{l}\text { Suatu lembaga pendidikan disebut bermutu jika telah terjalin kepuasan pelanggan atas jasa yang } \\
\text { erikan oleh lembaga pendidikan itu. Para pelanggan layanan pendidikan menurut Salis (2006) dibag } \\
\text { ijadi empat kelompok, yaitu: Pertama yang belajar, bisa merupakan mahasiswa/pelajar/siswa } \\
\text { erta belajar yang biasa disebut klien/pelanggan primer (primary external customers). Mereka inilah } \\
\text { g langsung menerima manfaat layanan pendidikan dari lembaga tersebut. Kedua, para klien terkai } \\
\text { gan orang yang mengirimnya ke lembaga pendidikan, yaitu orang tua atau lembaga tempat klier } \\
\text { ebut bekerja, dan mereka ini kita sebut sebagai pelanggan sekunder (secondary external customers) } \\
\text { anggan lainnya yang ketiga bersifat tersier adalah lapangan kerja bisa pemerintah maupun masyaraka } \\
\text { gguna output pendidikan (tertiary external customers). Selain itu, yang keempat, dalam hubungar } \\
\text { embagaan masih terdapat pelanggan lainnya yaitu yang berasal dari intern lembaga; mereka itu adalah } \\
\text { guru/dosen/tutor dan tenaga administrasi lembaga pendidikan, serta pimpinan lembaga pendidikar } \\
\text { ernal customers). }\end{array}$} \\
\hline
\end{tabular}

\section{SIMPULAN DAN SARAN}

\section{Simpulan}

Dari hasil penelitian dan pembahasan di atas diambil beberapa kesimpulan sebagai berikut: (1) Implementasi SIM terpadu di SMK Kabupaten Malang sudah berjalan dengan baik dengan menggunakan model aplikasi yang dikenal dengan sebutan Master-Web. Implementasi meliputi bagian-bagian yaitu kurikulum, kesiswaan, hubungan masyarakat/industry, keuangan, ketenagaan, dan Bimbingan Konseling. Semua informasi dapat diakses oleh kepala sekolah sebagai bahan pengambilan keputusan meningkatkan mutu sekolah; (2) Hambatan diantaranya adalah masih adanya beberapa SDM yang tidak menguasai IT, kurangnya disiplin menginput data, kurangnya kepedulian beberapa SDM terhadap pentingnya informasi yang terintegrasi di sekolah, sarana prasarana yang kurang, lemahnya keamanan sistem yang digunakan, dan kurangnya komunikasi; (3) Strategi yang dilakukan oleh sekolah dalam mengatasi hambatan diantaranya dengan pelatihan IT, melakukan pengawasan manajemen, menyusun visi bersama, dan menciptakan hubungan yang harmonis; dan (4) Implementasi sistem informasi 
manajemen terpadu dapat meningkatkan layanan pendidikan di SMK Kabupaten Malang terlihat dari hasil informasi yang didapat pada tiap bagian dapat dimanfaatkan oleh pelanggan sekolah, baik pelanggan internal (siswa dan guru) maupun pelanggan eksternal (wali siswa dan dinas terkait)

\section{Saran}

Dalam implementasi program yang telah ditetapkan diperlukan kontrol dan evaluasi terhadap pelaksanaannya dari manajemen tingkat tertinggi (kepala sekolah). Fungsi manajemen harus benar benar dilaksanakan agar program berhasil sesuai tujuan. Untuk itu bagi peneliti selanjutnya bisa meneliti pengaruh kepemimpinan terhadap implementasi sistem informasi manajemen untuk meningkatkan layanan pendidikan di SMK, atau pengembangan Model SIM Terpadu yang berbasis Android untuk meningkatkan mutu sekolah.

\section{DAFTAR RUJUKAN}

Aditya, V. D., Sumadi, \& Sutarno, I. (2011). Implementasi Sistem Informasi Manajemen Terpadu Pendidikan. Sistem Informasi Manajemen, 01(01), 01-24.

Davis, Gordon B (Ed). (2002). Kerangka Dasar Sistem Informasi Manajemen bagian I Pengantar. Jakarta: Pustaka Binaman Pressindo

Moleong, Lexy. (2002). Metodologi Penelitian kualitatif. Bandung: Remaja Rosdakarya.

Nugroho, Riant., Dwidjowijoto. (2004). Kebijakan Publik: Formulasi, Implementasi, dan Evaluasi. Jakarta: PT. Elex Media Komputindo.

Peraturan Menteri Pendidikan dan Kebudayaan RI Nomor 34 Tahun 2018 tentang Standar Nasional Pendidikan SMK/MAK.

Prasojo, L.D. (2013). Sistem Informasi manajemen Pendidikan. Yogyakarta:UNY Press.

Rochaety, Eti dkk. (2009). Sistem Informasi Manajemen Pendidikan. Jakarta: PT Bumi Aksara.

Rusdiana, A., Moch. Irfan. (2018). Sistem Informasi Manajemen. Bandung: Pustaka Setia.

Salis, Edward. (2006). Total Quality Management in Education. [terj]. Yogyakarta: IRCiSoD

Sugiyono. (2012). Metode Penelitian Kuantitatif Kualitatif. Bandung: Alfabeta.

Triwiyanto, T. (2019). Gelombang Liberalisme Pendidikan Mengawal Tata Kelola Pendidikan Untuk Rakyat. Jakarta: Kompas.

Undang Undang Republik Indonesia Nomor 20 Tahun 2013 tentang Sistim Pendidikan Nasional.

Utama, H. B., Wachidi, W., \& Somantri, M. (2019). Implementasi Sistem Informasi Manajemen Di Sekolah Menengah Kejuruan (Smk) Muhammadiyah 1 Padang. JMKSP (Jurnal Manajemen, Kepemimpinan, Dan Supervisi Pendidikan), 4(2), 225.

Wahyudi, Apri., Sowiyah, \& Ambarita A. (2015). Implementasi Sistem Informasi Manajemen akademik Berbasis WEB (Studi kasus di SMK Negeri 3 Metro)", Jurnal FKIP Universitas Lampung.

Yakub., \& Hisbanarto, V. (2014). Sistem Informasi Manajemen Pendidikan. Yogyakarta: Graha Ilmu. 